\title{
Correction to: Fast nuclide identification based on a sequential Bayesian method
}

\author{
Xiao-Zhe Li ${ }^{1}$ (D) Qing-Xian Zhang ${ }^{1}$ (D) $\cdot$ He-Yi Tan ${ }^{1} \cdot$ Zhi-Qiang Cheng $^{1}$ (D) \\ Liang-Quan $\mathrm{Ge}^{1}{ }^{1} \cdot \mathrm{C}^{-}$Guo-Qiang Zeng ${ }^{1} \cdot$ Wan-Chang Lai ${ }^{1}$
}

Published online: 5 March 2022

(C) The Author(s), under exclusive licence to China Science Publishing \& Media Ltd. (Science Press), Shanghai Institute of Applied Physics, the Chinese Academy of Sciences, Chinese Nuclear Society 2022

\section{Correction to: NUCL SCI TECH (2021) 32:143 https://doi.org/10.1007/s41365-021-00982-z}

In the original article, the funding information were missing and in this correction the funding information is given below:
Funding This work was supported by the National Natural science Foundation of China (No. 41774190), the Special-funded program on national key scientific instruments and equipment development (No. 2017YFC0602105), and the Department of Science and Technology of Sichuan Province (No. 2020JDRC0109).

The original article has been corrected.

The original article can be found online at https:// doi.org/10.1007/s41365-021-00982-z.

Qing-Xian Zhang

shinecore@163.com

1 Chengdu University of Technology, The College of Nuclear Technology and Automation Engineering, Chengdu 610059, China 